\title{
AN EXPERIMENT IN TEACHING ARITHMETIC IN THE THIRD GRADE
}

\author{
MARY L. DOUGHERTY \\ Formerly, State Teachers College, Mankato, Minnesota
}

There is probably nothing in arithmetic work in the primary grades that presents more difficulties than the process commonly known as "carrying" or "adding" in addition and multiplication, "borrowing" in subtraction, and the similar process in division. All of these processes may be termed "reduction." In addition and multiplication the reduction is from a lower to a higher order. In subtraction and division the reduction is from a higher to a lower order.

With the idea of attempting to find a way that would rid this work of its drudgery and help the children to understand what they are doing, the experiment here described was undertaken with a third-grade class. The question has often been raised as to how far it is desirable to rationalize these processes in teaching children and how far it is better merely to teach the method. The theory on which this work was based is that if the process is rational and the child has reached a stage where he is fitted to use it, he can himself develop the process so that it has meaning for him and he has a reason for its use. An attempt was made, therefore, to teach these processes inductively.

Early in the year addition was introduced. After adding single columns, the class was given an example of two columns, as 26, and asked to add. They gave the answer to the first column (I5) $3^{2}$

without difficulty. The question was raised by the teacher, "How shall we write this?" Then the units column was copied to one side, and one of the pupils readily placed the answer correctly- 
the one ten well separated from the five units so that it was evident that there were two columns. Then the class was asked, "Why can you not write it so here?" The answer was given, "Because there is another column there."

Teacher: Is there anything we can do?

Child: We could add it in with the others.

Teacher: Why do that?

Child: Because it belongs in that column.

Teacher: How shall we know we are to add it there?

Child: We could write it above the line.

This was done to the satisfaction of the class. The children without suggestion adopted the habit of writing the I above the line and then writing the 5 in its place below the line: 26 . This was

5

a surprise to the teacher, but it eliminated entirely the problem which often troubles children as to which to "write" and which to "carry," and the customary formula was never used. Thus time was saved. For several days the teacher kept strict watch over the work, but there did not seem to be any confusion in the minds of even the slowest children. Here and in multiplication there was no effort to break the habit of writing above the line the figure to be added. This was because it is a generally accepted method in adding or in multiplying to keep the carried figure for the sake of economy in checking in case of error. For example, an error in the third column may be checked by adding that column and the number to be added from the second column instead of re-adding all of the columns. If the figures are properly made and placed, there is no danger of confusion such as is almost certain to arise in using "helping figures" in subtraction or division.

After this process in addition was established, the process of multiplication with reduction was taken up because this presents the same type of reduction as addition. Preliminary to this, the children were given many examples of the type, 8I. Then they 
were given the example 43 and asked to solve it, being told that $\times 6$

there was something new in it. When they discovered that they could go no farther than the first product (I8), this combination was placed at one side and the answer written. Here the fact that they had the habit of correct column placing helped. They were shown an example in addition similar to the one presented and asked what they did there. After a little study one child responded, "Oh, I know. We can write it above the line in the next column." This was done: 43 . Then there was a little confusion as to how $\times 6$

I

8

to use it. They were asked what they were to multiply.

Child: Forty-three.

Teacher: You have multiplied the 3. What must you do now?

Child: Multiply the 4 .

Teacher: What will that give?

Child: Six 4's are 24 .

Teacher: Now what shall we do with the I?

Child: Add it.

Both of these processes are relatively simple compared with that of subtraction with reduction. Before this was taken up, the work was carefully analyzed by the teacher into various stages of difficulty. It was presented in connection with problems in United States money, as is frequently done. The first reduction required was from dollars to dimes, as it was thought that this process would be easier for the child to image than the reduction from dimes to cents. Then ciphers appeared, first in the answer, then in the subtrahend, then in the minuend. When the children had become proficient in examples with United States money, the process unaccompanied by the money symbols was introduced.

Finally, six months after the first presentation, the children were given examples requiring two reductions. In preparation for this work the children were given much drill on subtraction combinations in which the minuend was from to to 18 and the subtrahend from I to 9, with the subtrahend always larger than the units 
figure of the minuend. This was done for the purpose of fixing the number facts necessary in any example in subtraction where reduction is required.

The presentation was made in the following manner:

Teacher: I went downtown with \$1.29 in my purse. I wanted to buy something that cost 75 cents. [This was written on the board in subtraction form and the suggestion made:] Let us see if we can find out how much money I took home. First tell me this: What pieces of money might $I$ have in my purse?

Child: You could have a dollar bill.

Teacher: Yes, I will mark this $\left(\begin{array}{l}\$ \\ \mathrm{I}\end{array}\right)$ to show it is a dollar. How could I have twenty cents?

Child: You could have two dimes.

Teacher: I will mark it $d$ for dimes. How might I have the rest ?

Child: You could have a nickel and four pennies.

Teacher: Yes, how else could I have it?

Child: You could have nine pennies.

Teacher: What do you call one penny?

Child: One cent.

Teacher: Then can we call this nine cents? [Accepted and $c$ written above the 9.]

Teacher: Now let us look at this: $\$ d c$. If I have nine cents, I can pay $\$ 1.29$

$-.75$

out five cents, can't I ?

Child: Yes.

Teacher: What shall I have left?

Child: Four cents.

This was written in its proper place.

Teacher: Now, I have how many dimes?

Child: Two.

Teacher: How many dimes do I want to spend?

Child: Seven.

Teacher: Can I spend seven dimes if I have only two?

Several children answer, "No." One child, "Yes, you can. Break your dollar."

Teacher: If I break my dollar, how many dimes can I get from it?

No one remembers. The children count and find that there are ten. 
Teacher: I had two dimes. How many shall I have now?

Child: Twelve dimes.

Teacher: If I have twelve dimes, can I spend seven dimes?

Child: Yes. [Pause.] You will have five dimes left. [This was written.]

Child: Then you will have one dollar and fifty-four cents left.

Teacher: Shall I?

Class studies the example.

Child: No, you broke your dollar. You have just fifty-four cents left.

Several similar examples were given. The questions asked were, "Can I spend six cents?" "Can I spend four dimes if I have only two?" "What can I do?" The answer to this question was always that given by a child the first time, "Break your dollar." Then the question was asked, "What shall I have left ?" No "helping figures" were written in, and the children never heard the formula, "four from two you cannot take," etc.

The children were very much interested, and after several examples had been worked one of the class said, "Put 2 there and see if it will do it."

Teacher: Do you mean use two dollars instead of one dollar?

Child: Yes.

This change was made to the satisfaction of most of the class, but the boy who had suggested it said, "You don't need to take just one dollar. You can use the two dollars."

Teacher: Yes, so you can, but what is the use? If you had ten one-dollar bills in your pocket and owed a man seven dollars, would you give him all of them?

Another child answered, "No, don't give him any more than you have to."

The boy agreed to this.

Teacher: How much do we have to use here? [indicating the example on the board].

Child: One dollar.

Teacher (to boy who asked): Shall we do it so?

Child: Yes.

From here the advance was made to five dollars and twentyseven cents and to any number of dollars not exceeding nine with dimes less than those to be spent and cents more than those to be 
spent. The introduction here was, "I have been to the bank and have more money to spend." Then one of the children said, "That is what my father does in his bankbook."

Teacher: Yes. Why does he do it?

Child: So he won't spend more than he has in the bank.

Teacher: Then, if we want to have money in the bank, should we know how to do this?

Child: Yes.

Child: I see how to do it all right, but the trouble is I do not always know what numbers to put down.

Teacher: Why is that?

Child: Because I don't know the subtraction answers [combinations] well enough.

Others admitted this trouble.

Teacher: What can you do?

Child: Study them.

This became the incentive for intensive drill on the subtraction combinations.

For three weeks the class was given no advance step in this work, and frequent drill was given on such examples. Then the class was told one day that they had done so well that they might have something new. An example like $\$ 7.64$ was given. They

$$
-2.38
$$

were reminded of the columns showing dollars, dimes, and cents. Then they were asked, "If I have four cents, can I pay out eight cents?"

Child: No, but you can use a dime.

Teacher: How many cents are in a dime?

Child: Ten cents.

Teacher: Then how many cents have I ?

Child: Fourteen cents.

The subtraction proceeded.

Child: Three from 5 leaves 2.

Teacher: Why isn't it 3 from 6 ?

Child: You used one dime.

The children recognized this as natural without "crutch" or formula. When a child occasionally forgot, the question, "Why is it not 3 from 6 ?" recalled the fact, and he corrected himself. 
The matter was never explained to the class. They offered their own explanations whenever a difficulty arose. Two reductions were not required in the same example at this stage. The next advance after practice drill on this step was to mix it with the first step.

The cipher was then introduced, first in the answer, then in the subtrahend, then in the minuend, with periods of practice on each new step before the introduction of the next. The last of these, the cipher in the minuend, presents particular difficulty because it requires reduction from dollars through dimes to cents. The example, $\$ 7.04$, was given.

$$
-2.86
$$

Child: Six from I4 leaves 8.

Teacher: How did you get $\mathrm{I}_{4}$ ?

Child: I used a dime.

Teacher: There are no dimes [indicating on the board].

One child, after hesitation and study on the part of the class, suggested, "You will have to break a dollar." Class agreed.

Teacher: Then what shall we have?

Child: Ten dimes.

Teacher: Shall we use them all?

Child: No. Use only one dime.

Teacher: Do you all agree?

Child: I see that it is 6 from $\mathrm{I} 4$, but what do we take 8 from? get?

Teacher: See if we can find out. When we broke the dollar, what did we

Child: Ten dimes.

Teacher: How many dimes have we used?

Child: One.

Teacher: Then how many dimes have we now?

Child: Nine dimes.

Teacher: What shall we take 8 from?

Child: Oh, I see. Eight from 9 leaves I.

The example was then completed. Two from 6 leaves 4 .

Teacher: Why is it 2 from 6 ?

Child: Because we broke one dollar.

At this time it was decided to give the children the transition from subtraction using United States money to subtraction where abstract numbers are involved. An example such as they had used was placed on the board and worked. The same example was 
written again, omitting the dollar sign and the decimal point, with the statement, "Now I am going to give you something new." One boy remarked, "You forgot your dollar sign and decimal point." His criticism was recognized with a smile and the statement, "We'll go on." The subtraction was carried on without a question and with no evident recognition that an example had been repeated. When it was finished, all inspected it.

Child: We have the same answer as last time.

Teacher: Is that so?

Child: No, we haven't. The first answer is 9 dollars and 76 cents, and the other is 9 hundred 76 .

Teacher: Is this right? [indicating the last].

Children inspect and say it is.

Teacher: Can we subtract numbers that are not money?

Children consider and then answer, "Yes."

Teacher: What might this be? [last example].

Child: It could be all dollars.

Teacher: Yes. Could it be anything else?

Child: It could be potatoes.

Teacher: Yes, what else?

A long list was given. Several examples were then given stating problems, as, "I had 764 bushels of potatoes and sold 346 bushels. What had I left?" 764. From that time no difference $-346$

was made between the abstract and the concrete forms.

The work from the introduction to this stage covered a period of six months, during which time the children were keeping up their practice on the other processes that had been taught.

The next step to be introduced was subtraction where two reductions are required in the same example: 734 . It was antici$-286$

pated that there might be trouble here.

The first child was confused. The teacher gave an example like the first ones presented and let this child work it and asked for explanations at each step. Then the child worked the new example without help. During the period each child worked one example 
without any question as to the procedure. When asked why it was 8 from I2, or 2 from 6, they answered promptly, "You used one."

This method of teaching has several advantages. The children understand it because they have discovered it. They have no habit to break such as they have when they have learned the formula and used the "helping figures." It is economical in time and effort for all concerned. It prevents the unsightly pages made by writing in the "helping figures" and avoids the confusion likely to arise.

Inexact division was the last process introduced. Much practice in exact division with the tables which were known preceded this.

The theory which formed the basis for the following method was that a large contributing cause to mistakes in division is lack of knowledge of the appropriate exact product for the example being worked. For this reason examples requiring reference to only one table were used in any one period. The products in this table were written on the board above the place where the work was to be done. These were first put on in regular order, but soon the children gave them, and they were placed on the board at random. At first, an example in exact division with only one figure in the quotient was given,

as $7 \longdiv { 5 6 }$. Immediately below this were given in serial order all of the inexact divisions to the next product, $7 \longdiv { 5 7 }, 7 \longdiv { 5 8 }, 7 \longdiv { 5 9 }, 7 \longdiv { 6 0 }$, $7 \longdiv { 6 1 }, 7 \longdiv { 6 2 }$. The children worked many examples like this in different series until one child remarked, "I know that because it is always just one more over," indicating that he understood how the fractional remainder was obtained. The teacher expressed mild surprise at the statement, and the class verified it by studying the work on the board and finding it to be true. To make sure that all understood this part of the process the next step was taken.

Teacher: Then see if you can work them when I write them differently.

An exact division example was given and under it inexact divisions involving the same integer quotient but not in serial order. The children discovered that they must subtract the exact product 
from each dividend, as 56 from 6r. This type of drill was carried on for about three weeks. The next step was to place all of the products at the top of the board without calling attention to the particular product to be used in the example being considered. An example like 7) 69 was placed on the board and the children asked to find in the products above the one they should use for working this example. After two or three examples had been worked, one of the children said, "You always have to find the one that is nearest."

Teacher: Is that true?

The next example was $7 \longdiv { 5 4 }$, and a child gave 56 .

Teacher: That is nearest. Is it the one we need ?

After looking at it, one child said, "No, it is too large."

Teacher: What shall we use?

Child: Forty-nine.

Teacher: Now can you tell me how to know which number to use ?

Child: You have to use the nearest one that is smaller.

A great deal of practice was given at this stage. At first the required order was, "Use 49 . In 49 there are 7 sevens. In 54 there are 7 sevens and 5 over, five-sevenths." This order was followed merely to fix in the child's mind the process of referring to the exact product and of recognizing the factor which would give the quotient in the example. After some time first one child and then another shortened the statement, saying, "Forty-nine; in 54 there are 7 sevens and five-sevenths." This was recognized by saying, "You may do it in your mind if you can do it more quickly that way." Whenever any uncertainty was manifest the full form was recalled.

When most of the children worked easily by merely referring to the products and, without naming them, working the example, the next step was taken up. This was to teach division where two figures are required in the quotient. Several examples such as had been used for some time were given and worked. Then the teacher said, "I am going to change this first example and see if you can work it." The integer in the quotient was left and a digit added which with the remainder would give an even division 
for the second figure of the quotient. Naturally the children did not know what to do. It did not seem necessary to begin with United States money as the children had made the transition in subtraction to the use of abstract integers. Therefore, the following method was used: The example $8 \longdiv { 7 ^ { \frac { 6 } { 8 } } }$ had been worked. This was changed so that it stood $8 \longdiv { 7 8 4 }$. The dividend was written at one side (784), and the children were asked to read it. Then the teacher asked, "This is 7 what? [pointing]. When we read it we say $7-$ ?"

Child: Seven hundred.

Teacher: We will mark it so that we will remember $\stackrel{h}{(784)}$. Now tell me what we have besides the 7 hundred.

Child: Eighty-four.

Teacher: Yes, that is 80 and how many more?

Child: Four more.

Teacher: Suppose we write it $80+4$ [written as spoken]. Now 80 is eight what?

Here the class seemed puzzled.

Teacher: How many 8's in 80 ?

Child: Ten 8 's are 80.

Teacher: How many Io's are 80 ?

Child: Eight ro's are 80.

Teacher: Eight what are 80 ?

Child: Eight tens are 80.

Teacher: Then this 8 [indicating the 8 in 784 ] is what?

Child: Eight tens.

Teacher: We will mark it so: $\stackrel{h t}{(784)}$. The 4 is 4 what?

Child: Four I's.

Teacher: Yes. There is a name we give that. We say units when we have a number less than ten. [The word is written on the board and pronounced.]

Teacher: Shall we write it here? $\stackrel{h t u}{(784)}$

Child: Yes.

Teacher: Let us tell what each of these is [indicating as the class says, “ 7 hundreds, 8 tens, 4 units"]. 
Teacher: Now let us come back to our example and mark the figures. Then we shall see if it will help us.

$$
\begin{aligned}
& \frac{9}{h t u} \\
& \text { 8) } 784 \text {. }
\end{aligned}
$$

Teacher: The first part is right as we worked it. Tell us again so we will be ready to go on.

Child: In 78 there are nine 8's (72) and 6 over.

Teacher: Good. How did you find the 6 over?

Child: I took 2 from 8.

Teacher: What is the 8 ?

Child: Eight tens.

Teacher: Then the two is - ?

Child: Two tens.

Teacher: And the 6 ?

Child: Six tens.

Teacher: Six tens are what?

Child: Six tens are 60.

Teacher: And four are - ? [pointing to the example].

Child: Sixty-four.

Teacher: How many 8's in 64 ?

Child: In 64 there are eight 8 's.

Teacher: Yes, and we must write it directly above the four $8 \longdiv { 7 8 4 }$. Now let us try one of the others.

During the first period all of the examples given were those which the children had worked in simple form changed so as to require the reduction. If there was any hesitation, the children were required to name the product to be used in the table, as $8 \longdiv { 5 8 4 }$ : "Fifty-six. In 56 there are seven 8 's. In 58 there are seven 8 's and 2 over. Two tens are 20 and 4 is 24 . In twenty-four there are three 8's."

The children of their own accord shortened the form as soon as they saw the process clearly. When they did so they were told, "You may do it in your mind if you can do it more quickly that way." If they could not, they continued to give all of the steps. Here as in subtraction, they never used any helping figures. They did not need them because they understood how the new dividend was found. 